\title{
FAK Inhibitor PF-00562271
}

National Cancer Institute

\section{Source}

National Cancer Institute. FAK Inhibitor PF-00562271. NCI Thesaurus. Code C78199.

An orally bioavailable small molecule and ATP-competitive focal adhesion kinase (FAK)

inhibitor with potential antineoplastic and antiang iog enic activities. FAK inhibitor PF00562271 inhibits the tyrosine kinase FAK, and to a lesser extent, proline-rich tyrosine kinase (PYK2), which may inhibit tumor cell migration, proliferation, and survival. As FAK is a signal transducer for integrins, inhibition of FAK by this agent may prevent integrinmediated activation of several downstream signals including ERK, JNK/MAPK and PI3K/Akt. FAK and PYK2, upregulated in many tumor cell types, are involved in tumor cell invasion, migration and proliferation. 